\title{
Development of antimicrobial finish from false daisy (Eclipta alba) for cotton fabric
}

\author{
KHUSHWINDER KAUR, SANDEEP BAINS AND SUMEET GREWAL
}

Received: 15.02.2016; Revised: 15.04.2016; Accepted: 29.04.2016

$\underline{\text { See end of the paper for authors' affiliations }}$ KHUSHWINDER KAUR Department of Apparel and Textile Science, College of Home Science, Punjab Agricultural University, LUDHIANA (PUNJAB) INDIA Email : khushgill14@gmail.com
ABSTRACT : Soxhlet method was used for the extraction of False dasiy with methanol. The antimicrobial activity of false daisy extract was determined by the Disc diffusion method and determine the optimum values of three concentrations 3, 5, $7 \mathrm{~g} / \mathrm{lit}$. and time values 12, 18, 24 hours whereas temperature, medium and $\mathrm{pH}$ used for optimization of extraction conditions were kept constant. False daisy extract was applied on cotton fabric by direct and microencapsulation techniques. The physical properties of untreated and treated fabric were assessed to determine the appearance, performance and serviceability of the fabric. The test samples were assessed for fabric weight, thickness, drapability, bending length, flexural rigidity, crease recovery, moisture regain, tensile strength, elongation, whiteness index using standard test methods. The efficacy of the microencapsulated samples assessed by testing antimicrobial activity after 5, 10, 15, 20 launder-o-meter washing cycles. The absorbance value of microencapsulated sample after 0 washes 1.102 and 1.757 even after 20 washing cycles. False daisy shows greater reduction of bacterial growth. The antimicrobial activity of microencapsulated sample significantly reduced after every washing cycle.

KEY WORDS: Antimicrobial, Cotton, Efficacy, Optimization, Microencapsulation

- HOW TO CITE THIS PAPER : Kaur, Khushwinder, Bains, Sandeep and Grewal, Sumeet (2016). Development of antimicrobial finish from false daisy (Eclipta alba) for cotton fabric. Asian J. Home Sci., 11 (1) : 88-92, DOI: 10.15740/HAS/AJHS/11.1/88-92. 